\title{
Genre-Based Approach to the Analysis of Introductions in Doctoral Seminars of the Department of English, UNIZIK, Awka
}

\author{
Chinwe Ezeifeka \\ http://dx.doi./org/10.4314/ujah.v21i2.1
}

\begin{abstract}
This paper analyses selected research article introductions of doctoral seminars in the Department of English Language and Literature, Nnamdi Azikiwe University, Awka, to determine how these academic writings follow specific formats characteristic of such genres. Specifically the work looks at the staged cognitive organisation of the selected samples in line with the requisite schematic or generic structure postulated in Bhatia (1993) and adopted by the University of Southern California (USC). Every genre is characterized by culture-bound unique structuring and communicative purposes that give it generic coherence. Research article introduction is an academic sub-genre with specified conventions characterising genres from the academic culture/community. A total of eighteen samples of research introductions were analysed, the aim being to determine whether the cognitive move structures in the samples conform with, or depart from, the conventionalized patterns of this academic sub-genre and how the pattern used in the samples enabled or militated against the writers' achievement of the desired communicative purposes. A critical reading of doctoral seminars in the Department shows lack of knowledge of the unique formatting of introductions, making this work to be anchored on English for Specific Purposes (ESP) with particular emphasis on English for Academic Purposes (EAP). The baseline of the findings is to discover the present proficiency of these group of learners, enlighten budding academics on the move structure of article introductions in order to achieve generic coherence as well as target proficiency in that sub-genre of academic writing.
\end{abstract}


Keywords: genre, schematic structure, generic structure, cognitive moves, research article introductions, doctoral seminar, academic writing

\section{Introduction}

Academic writing in tertiary institutions requires knowledge of the specialized communicative event, communicative goals and purposes of that particular discourse community. As a member of the academia, several years of experience acquired from reading students' research works ranging from undergraduate projects to master's theses and doctoral dissertations reveal these group of learners as having limitations in achieving their communicative intentions, partly, owing to poor knowledge of the conventional ways of discourse organisation in that genre. Writing research article introductions and abstracts both different sub-genres of academic writing particularly research reports - have been identified as posing serious difficulties for some students who are grappling with the various final projects in partial fulfilment of their faculty requirements for graduation. Some of the problems relate to poor knowledge of the code for academic writing which require proficiency in nominalized rather than clausal forms (Ezeifeka, 2015, Halliday 2004), knowledge of the conventions of each genre and sensitivity to cognitive structures and organizational formats (Bhatia, 1993 ).

Genre-based approach to writing and the study of texts like research article introductions has preoccupied many researches in academic writing with the quest to determining their inherent functional patterns vis-à-vis their communicative purposes. Members of what sociologists call "secondary cultures" write the way they do because textual and lexicogrammatical features are genre-specific and can only operate in a particular socio-cultural context and not in others. Previous studies in this area (Bakhtin, 1986; Martin, 1985: 25, 248; Hasan, 1978; Bhatia, 1993, 1997; Eggins, 2004), including a 
collection of chapters edited by Bazerman, Bonini and Figueiredo (2009) show that knowledge of generic structurego a long way in organizing text production and consumption in terms of predictable expectations and understanding of the myriad of genres in our culture.

In spite of arguments on whether genres should be understood in fixed, rigid schema, made up of stages, or whether genres are more flexible, unpredictable and heterogeneous, just like casual conversation, the need to have a uniform format for some specialized forms of writing such as academic writing, which research article introduction is a part, is incontrovertible. In this paper, an attempt is made to scrutinize research introductions as a genre in selected doctoral seminars of the Department of English Language and Literature, Nnamdi Azikiwe University, Awka. The paper will address the following questions: How are the introductions in the selected seminar papers organized structurally? How do these structural organizations conform with or detract from the known generic/schematic structure characterizing such a genre? How do the findings speak to the present proficiency of these students? What recommendations should be made for improving the anomaly?

The goal of this paper is therefore to discover the extent to which these selected texts from the Department of English Language and Literature conform to, or depart from, the stipulated schematic or generic structure of such a genre. Knowledge of such models and competent application of appropriate schematic structure to the writing of research introduction is germane for any budding academic who requires proficiency in language use in such a genre to be able to scale through their studies with good grades in seminar presentations as well as in their final projects. This work is therefore a contribution to the English for Specific Purposes (ESP), with particular emphasis on English for Academic Purposes (EAP), where a needs analysis of students' present proficiency, exemplified in the sample seminars, would lead to the determination of their present proficiency, their 
lacks and efforts to bring about learning that will lead to target proficiency. We shall proceed in this paper with reviewing the key concepts, thereafter its theoretical and methodological underpinnings. Analysis of data follows after which the paper concludes with a recommendation on the need for conscious learning, through ESP/EAP, of this important genre in academic writing.

\section{Conceptual Review}

\subsection{Genre}

The word genre is derived from the Latin word meaning kind or class (Wales, 1997; 1989). Widely used in literary criticism, the earliest classification of the concept dates back to Plato and Aristotle and defined loosely as "type" (Jones and Holmes, 2011: 87). This earliest period seemed to restrict the concept to literary disciplines where drama, poetry and fiction (prose) are referred to as literary genres. However, the meaning of the term has been extended to non-literary circles as "text-types" or "activity-types" incorporating any "type of discourse that occurs in a particular setting, that has distinctive and recognizable patterns and norms of organisation and structure, and that has distinctive communicative functions" (Richards \& Schmidt, 2010: 245). Swales' definition of a genre has been adapted by Bhatia (1993: 13) as:

(R)ecognizable communicative event characterized by a set of communicative purpose(s) identified and mutually understood by the members of the professional and academic community in which it regularly occurs. Most often, it is highly structured and conventionalized, with constraints on allowable contribution in terms of their intent, positioning, form and functional value. These constraints however are often exploited by expert members of the discourse community to achieve private intentions within the framework of socially recognized purpose(s). 
Martin's (1984: 25) definition of a genre as "a staged goaloriented purposeful activity in which speakers engage as members of our culture" and its modification as "how things get done, when language is used to accomplish them" (Martin, 1985: 248) emphasize the unique, recognizable textual structuring of different genres that uniquely reflect the different activity types. This means that there are many different genres as there are recognizable social activity types in our culture. It also presupposes that in constructing any genre, ranging from business reports, all legal documents, news broadcasts, speeches, letters, advertisements, and in our case in this paper, research article introductions, the writer must employ certain features conventionally consistent with other such texts from the genre in which he/she is writing, in much the same way as the reader anticipates certain features of the text based on genre expectations.

For scholars working in the systemic functional linguistic (SFL) tradition, that sees language as a meaning-making resource in context, genre is "one element in a complex social semiotic system" (Swales, 2004: 3). Eggins (2004: 54), writing in SFL view, refers to a genre as the "context of culture" in texts, closely related to the "context of situation" which is register. According to Eggins, for a text to have contextual coherence, it must make sense to the reader in its register and genre, what she called "registeral coherence" and "generic coherence" (2004: 29). These two contextual coherences guide the reader to decode from the word choices and structural/realizational patterns respectively, the field of, and participants in, the discourse, as well as the discourse community that generates such discourse. A text is said to have registeral coherence "when we can identify one situation in which all the clauses of the text could occur ... when we can specify for the entire collection of clauses the domain the text is focusing on (its field), what roles the writer or interactants are playing (its tenor), and how closely language is tied to the experience it is commenting on (its mode). On the other 
hand, a text has generic coherence when we can recognize the text as an example of a particular genre... when we can identify a unified purpose motivating the language (for instance, it tells a story or accomplishes a transaction), usually expressed through predictable generic or schematic structure.

Texts of the same kind therefore display what Eggins (2004: 55) refers to as "generic identity" - that is, negotiating texts depends in part on identifying ways in which a particular text is similar to, or reminiscent of, other texts circulating in the culture. It should be observed that some texts may exhibit similarity in register, and yet belong to different genres. For instance, Pare, Starke-Meyeering and McAlpine (2009: 179) have described the dissertation as a "multigenre" with "many readers" and "many readings". This assertion is obvious considering the different writing activities involved in producing a dissertation - abstracts, introductions, review of scholarship, methodology and analysis - all forming sub-genres of this high literacy genre. That is why it is essential that structural patterns or "schematic structure" of each text is studied to determine their generic identity. Generic coherence asks the following questions: What is the text doing? What is it trying to achieve? What is its cultural purpose? The major key concepts in most definitions of a genre are "text-type" or activity type", "communicative purposes/goals", "rhetorical moves" and "cognitive/schematic/generic structure". It is this generic structure that is our major concern in this paper, which Eggins (2004: 58), Martin (1985: 248) and Bhatia (1993: 30-34) have variously referred to as "schematic structure", "rhetorical moves" and "cognitive-move structure".

We can infer from the above assertions that for a text to be identified in a particular genre, that is, have generic identity, it must possess the following characteristics.

$>$ It must be cohesive; with cross-references of participants' interpretable conjunctive relations between sentences 
Ezeifeka: Genre-Based Approach to the Analysis of Introductions in Doctoral Seminars of the Department of English, UNIZIK, Awka

$>$ It must serve some communicative purposes in the particular culture it originates

$>$ It must show a recognizable schematic structure and realisational patterns by members of the culture.

Halliday (2004: 524-532) and Eggins (2004: 51) also argue that generic structure depends a lot on the "logogenetic" nature of texts which are basically cohesion and coherence. These text-dependent standards of textuality (De Beaugrande \& Dressler, 1981, in Carter \& Malmkjaer, 2002) which produce texture in texts help to glue elements of the text and its meaning together logically, sequentially and dynamically in a flow of thought. In this way, a context is created within which certain words become more likely to occur than others, and this allows readers to follow a recognizable logical sequence or textual pattern where he/she can predict and expect certain meanings as against others, thus contextualizing meanings in terms of expectancy.

Genre analysis thus involves the study of how language is used in particular contexts such as business correspondences, legal writing, staff meetings and - as this paper claims - academic writing which research article introduction shares the same field. Swales (2004: 13) claims that genres exhibit hierarchical characteristics, such that a genre may have a number of other sub-genres. To him, the research article is "at the privileged centre of a spider's web of interlocking genres" of which research article introductions, the focus of this paper, is one. Analysis of genres is therefore essential not only because genres and sub-genres differ in the different communicative goals, patterns of structuring and organisation, but also because readers need to be guided to make inferences on both local and global meanings of the text. Genre analysis enables analysts to study written texts to discover how writers conventionally sequence ideas and materials using functional labels that represent what van Dijk (2001:102-103) calls "macro-propositions" or "topoi" that 
encapsulate the various moves from the beginning of the text, to the middle and finally to the end. This includes the identification and activation of particular types of schema and how they are realized linguistically. In the next section, we discuss this schematic structuring.

\subsection{Schematic Structure}

Different genres tend to exhibit what could be assumed to be preferred ways of structural organisation to reveal their communicative intentions at each stage of the unfolding discourse. This may have informed Martin's (1985) definition of a genre as “... staged, goal-oriented purposeful activity...", each stage identified by a functional label called "rhetorical moves". Writers and speakers deliberately exploit and apply this staged unfolding of the text from its beginning to the end, and thus enable their readers to be able to identify and label the different macro-propositions or rhetorical moves, also known as generic stricture, cognitive structure or schematic structure (Bhatia, 1993; Burns \& Seidhofer, 2010).These concepts not only refer to the same phenomenon but also point to the fact that different text types display unique compositional patterns, and by identifying the macro-propositions of these texts, one can comprehend them more easily.

Although genres may contain both obligatory and optional elements in their schematic structure (Burns \& Seidhofer, 2010), Fairclough (1995: 13) argues on whether a genre should be understood as "a rigid schema made up of stages, all or some obligatory, in a fixed order... or whether genres are more flexible, unpredictable and heterogeneous", since many texts manifest complex mixed genres. Fairclough (1995: 14) gave an example of two genres job interview and family conversation over dinner. Whereas the former has predictable canonical structuring, the latter is more unpredictable and loose. It may therefore not be helpful, Fairclough 
argues, to conceive of a genre simply in terms of structuring with respect to stages. In spite of the above argument, Fairclough (1995: 13) admits that:

Nevertheless, the schematic view does have some reality as an ideal type and a convention - and some textual reality, in that some texts do adhere tightly to generic schemata. Even so, even at the level of greatest abstraction, only some genres have a tight schematic structure ....

In the midst of these contestations is the claim that writers of academic research adhere to some predetermined schematic structures in the many genres that make up academic writing such as introductions, abstracts and term papers. Swales (1981, in Bhatia, 1993) attests to the remarkable similarities in the organization of research introductions and abstracts. Bhatia (1993) posits four rhetorical move structures for the writing of research article abstracts: Problem-Methodology-Findings-Conclusion format as well as a fourmove structure for research article introduction. Since that is the focus of this paper, we shall first and foremost, discuss what research article introduction is and its importance in this field of academic writing.

\subsection{Introductions in Academic Research Writing}

Research article introductions serve the writer the avenue to showcase a preview of the topic, scope, intention and thesis (Spatt, 2011: 422). As a mental roadmap, a good introduction must answer the following questions:

- What am I studying/what is my research problem/what is my thesis statement?

- Why is this topic important to investigate?

- What motivates me to study this topic/problem?

- What do we know about this before/what and what have been done on this topic before? 
- What is left undone/what gap will my studying this topic fill/how will this study advance new knowledge or new ways of understanding this topic?

- What questions will the work address (what, how, why, to what extent etc)

According to the University of Southern California Research Guides (accessed 2019), the introduction leads the reader from a general subject area to a particular topic of inquiry by:

- establishing the scope, context and significance of the research,

- summarizing current understanding and background information about the topic,

- stating the purpose in the form of the research problem, supported by a hypothesis, or a set of research questions,

- explaining briefly the methodological approach used to examine the research problem,

- Highlighting the potential outcomes your study can reveal, and.

- Outlining the remaining structure and organisation of the work.

Bhatia (1993: 80) cited Swales' original four-move structure of a research article introduction:

Move 1: Establish field

(a) Showing centrality

(b) Stating current knowledge

(c) Ascribing key characteristics

Move 2: Summarizing previous research

(a) Strong author orientation

(b) Weak author orientation

(c) Subject orientation

Move 3: Preparing for present research

(a) Indicating a gap

(b) Question-raising

(c) Extending a finding 
Move 4: Introducing present research

(a) Giving the purpose

(b) Describing present research

Swales (1990) modified the above four-move structure into a three-move structure called the Create a Research Space (CARS) model. This model has been widely accepted (for instance, University of Southern California (USC) Research Guides, International Journal of Language Studies (IJLS) and most publishing outfits) as containing the relevant schematic structure/ rhetorical moves/generic structure of research article introduction. This paper therefore adopts this model in analyzing 18 seminar introductions of students of English Language and Literature to ascertain how far they conform to, or detract from, this generic structure. The specifications of the model are as follows.

Move 1: Establishing a territory/an area of research by:

Step I: Claiming centrality/highlighting the importance/motivations of the topic,

Step II: Making topic generalisations/making general statements about the topic,

Step III: Reviewing previous research/an overview of current research in the area,

Move 2: Establish a niche/Identify a research niche by:

Step IA: Counterclaiming/opposing an existing assumption and/or,

Step IB: Indicating a gap/revealing a gap in existing research, and/or,

Step IC: Question-raising/formulate research question(s) or problem(s), and/or,

Step ID: Continuing a tradition/continuing a disciplinary tradition. 
Move 3: Occupy the niche/place your research within the identified research niche by:

Step IA: Outlining purpose/stating the intent of your study

Step IB: Announcing present research/outlining key characteristics of your study

Step II: Announcing principal findings/describing important results, and

Step III: indicating article structure/giving a brief overview of paper structure.

What the above generic structure implies is that research article introductions must contain these three communicative purposes for it to be recognized as such, failing which it is flawed. The writer must, first of all, ensure that an area of research is identified, that previous studies are summarized in a manner that lays a foundation for understanding the research problem; secondly, explain how the research problem addresses gaps in literature: insufficient treatment of the topic, missing links, imbalances and other deficiencies in literature; and finally, note the broader theoretical, empirical and/or policy contributions and implications of the research.

Some writers go with the erroneous impression that research introductions are written before the commencement of the study. The University of Southern California (USC) states otherwise. It claims that:

It is often useful to review the introduction late in the writing process. This is appropriate because outcomes are unknown, until your've (sic) completed the study. After you complete writing the body of the paper, go back and review introductory descriptions of the structure of the paper, the method of data gathering, the reporting and analysis of results and the conclusion. Reviewing and if necessary rewriting the introduction ensures that it correctly matches the overall structure of the final paper. 
Ezeifeka: Genre-Based Approach to the Analysis of Introductions in Doctoral Seminars of the Department of English, UNIZIK, Awka

\section{Theoretical Framework}

The work is hinged on two theoretical assumptions: genre theory and English for Specific Purposes (ESP). Having extensively discussed the concept of genre and how knowledge of generic/schematic/cognitive-move structure enables writers and readers to organize texts in conformity with the cultures in which they are generated, we shall concentrate on how ESP provides the basis for this paper.

ESP, a relatively new approach to language teaching, aims to prepare the learner for specialized language use (Krashen, 1985: 89). It presupposes that we can teach the language of special fields deliberately by describing the special vocabulary and discourse rhetorical moves, writing out the exercises and teaching them to the learner. It studies specific language needs of learners and designs a course based on the findings of the needs analysis to meet these specific needs. The ultimate goal of such a course is to enable the learner function effectively in his/her profession or study referred respectively as English for Professional Purposes (EOP) and English for Academic Purposes (EAP) (Hutchinson \& Waters, 1987).

Bhatia (1993, 1997) made strong cases on the relationship between functional ESP course design and genre-based analysis. To him, only formal linguistic descriptions may be inadequate for learners who need more functional syllabi - which should include register analysis, discourse analysis and genre analysis - to equip them for job or study requirements. ESP practitioners agree that there exist differences between the types of English used by professionals in different disciplines: medical doctors, engineers, businessmen, administrators just like there exists specialized language of medicine, engineering, law, commerce administration and education. It means that language varies from one context of situation and culture to another and that is the essence of genre and register analysis. According to Hutchinson and Waters (1987: 8) 
If this was so, then it should be possible to determine the features of specific situations (and texts) and make these features the basis for the learner's course ... Tell me what you need English for and I will tell you the English that you need.

Needs analysis thus becomes the core feature of ESP: to discover the learner's present proficiency vis-à-vis the target proficiency in order to predict his/her lacks. According to Hutchinson and Waters (1987: 7-8), the learner's "lacks" is "the gap between the target proficiency and what the learner already knows" that is, his/her present proficiency. The motivation for learning is usually instrumental or utilitarian; students study English not because they are interested in the study of the English language as such, but because they need English for study or job purposes and this will have implications for the kinds of activities to present to the learners.

This paper thus sees research article introduction as a learning need for undergraduates whose projects have been scrutinized and analysed. In fact, Swales, (2004: 12) in emphasizing the integral nature of genre-based approach in ESP, suggests English for Research Purposes (ERP) as an aspect of inculcating this specialized writing knowledge. It is obvious from the present proficiency of these students, as seen in the analysis, that they need awareness of the schematic/generic structure of research article introductions to enable them achieve target proficiency. The following sections will highlight these areas of need and provide a model introduction that follows the move structures to fill this academic gap for this category of learners.

\section{Methodology}

The paper adopts a qualitative approach to the analysis of selected introductions in doctoral students' seminars, written between 2015 and 2019, when the present writer got approval to supervise doctoral students. Each of the selected seminar introductions contains an average of four pages written on a double-spaced, 12point, Times 
New Roman font, and so makes the texts quite voluminous. As a result, only eighteen of the introductions were purposely selected for the paper, nine each from the Language and Literature options of the Department. These introductions were carefully and conscientiously read to determine the needs of these budding academics in writing good introductions that follow the conventions of that genre.

Selected introductions were numbered from 1 to 9 in Tables 1 and 2 for each of the stress areas in the department. The introductions were adjudged good or bad (marked either $\sqrt{ }$ (good) or X (bad) on each column) depending on how far each segment of the text conforms to Swales (cited in Bhatia, 1993) CARS model also adopted by the University of Southern California (USC) research guides (accessed July, 2019). These models have been exemplified earlier in the review and their major cognitive moves and sub-moves are indicated in the tables.

\section{Data Analysis}

We present the eighteen selected seminar introductions in Texts 1 and 2, nine each from the Language and Literature options of the Department. Tables 3 and 4 summarize the schematic structure in each of the introductions studied alongside the omitted moves. In Table 5, we present a sample introduction, which incidentally is the introduction to this paper, to illustrate the schematic structure of a modest research article introduction. 


\subsection{Table 1: Selected Seminar Papers from the Language Option}

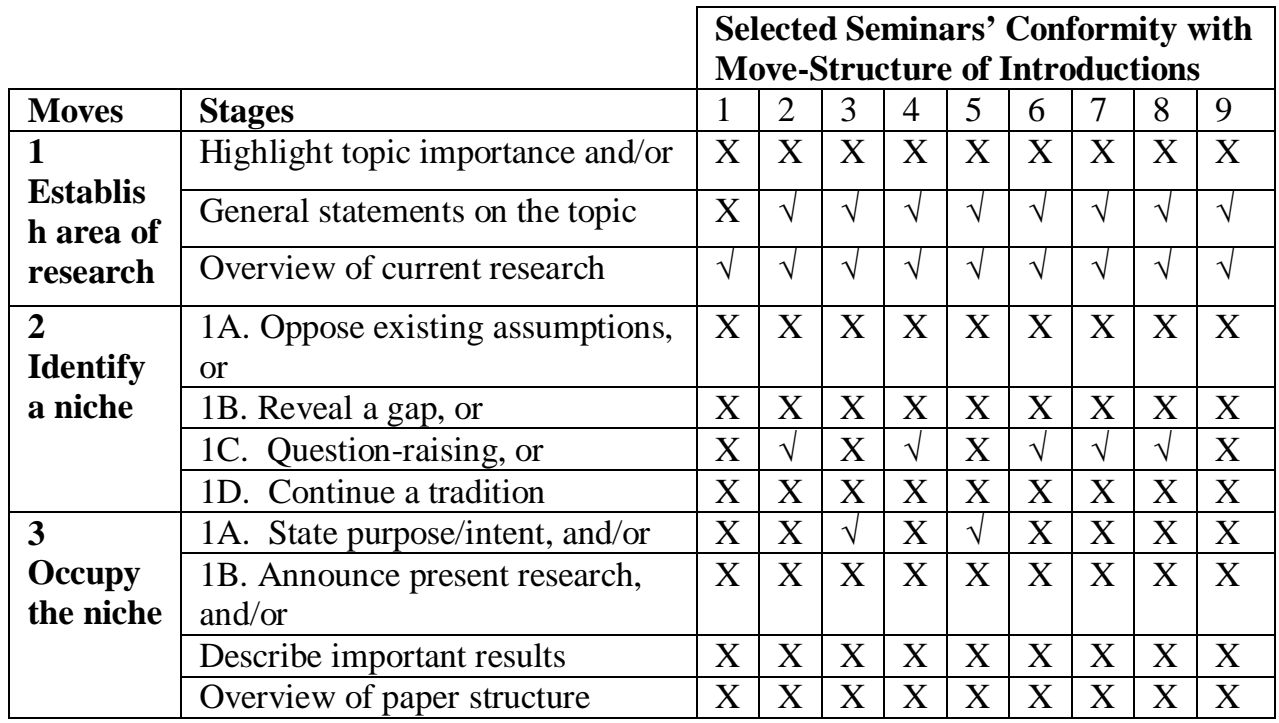

The above table shows how the selected sample of Nnamdi Azikiwe University Language Option doctoral students of the Department of English attained the requisite generic structure of introductions in their seminar presentations. The $\sqrt{ }$ sign shows conformity with the format while $\mathrm{X}$ shows deviation. From the table, the frequency of the negative sign over the positive is indicative of the problem that this work highlights. It is obvious that there is a lack in the students' present proficiency and target proficiency in this genre of academic writing. 
Ezeifeka: Genre-Based Approach to the Analysis of Introductions in Doctoral Seminars of the Department of English, UNIZIK, Awka

\subsection{Table 2: Selected Seminar Papers from the Literature Option}

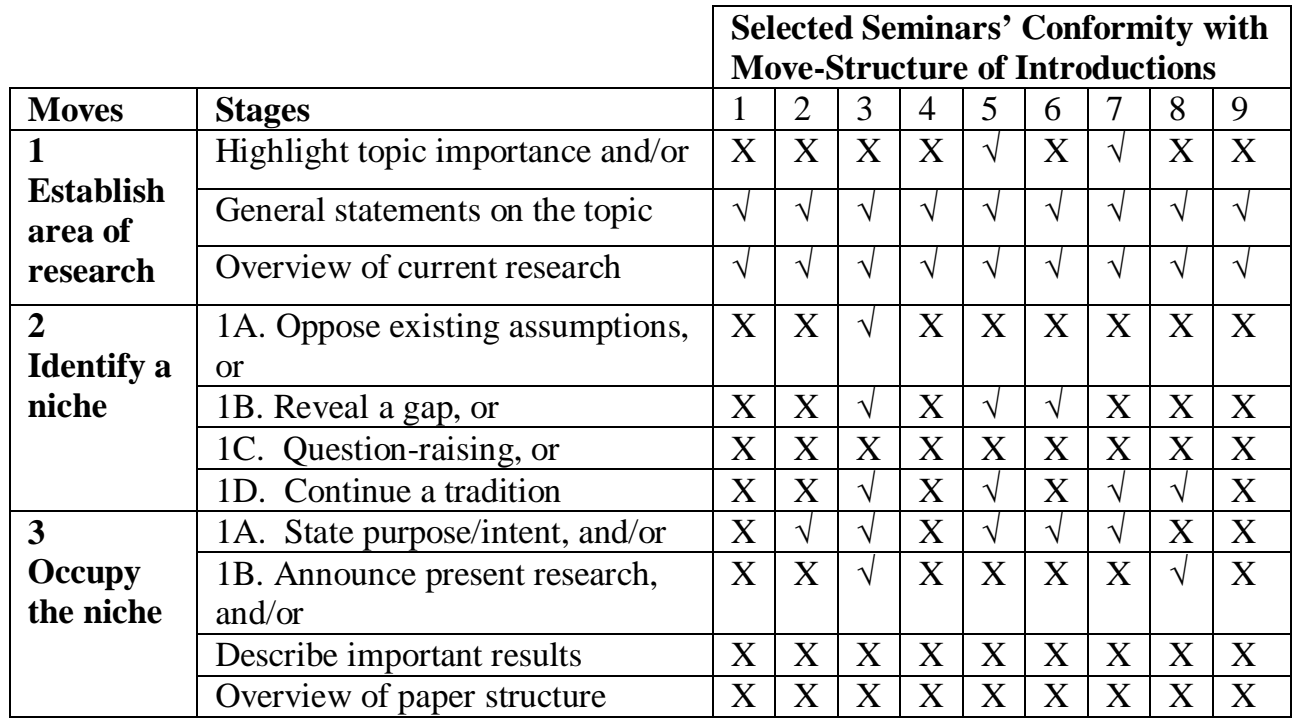

5.3. Table 3: Summary of Observed Generic/Schematic Structure in Language Option

\begin{tabular}{|l|l|l|}
\cline { 2 - 3 } \multicolumn{4}{c|}{} & \multicolumn{2}{|l|}{$\begin{array}{l}\text { Observed Generic/Schematic/Cognitive-Move } \\
\text { Structures in the Texts }\end{array}$} \\
\hline Texts & Moves and $($ Stages $)$ & Move $($ s) omitted \\
\hline $\mathbf{1}$ & Move $1(3)$ & Moves 2 and 3 \\
\hline $\mathbf{2}$ & Move $1(2 \wedge 3) \wedge$ Move $2(1 \mathrm{~B})$ & Move 3 \\
\hline $\mathbf{3}$ & Move $1(2 \wedge 3) \wedge$ Move $3(1 \mathrm{~A})$ & Move 2 \\
\hline $\mathbf{4}$ & Move $1(2 \wedge 3) \wedge$ Move $2(1 \mathrm{C})$ & Move 3 \\
\hline $\mathbf{5}$ & $\begin{array}{l}\text { Move } 1(1 \wedge 2 \wedge 3) \wedge \text { Move } 3 \\
(1 \mathrm{~A})\end{array}$ & Move 2 \\
\hline $\mathbf{6}$ & Move $1(2) \wedge$ Move $3(1 \mathrm{C})$ & Move 2 \\
\hline $\mathbf{7}$ & Move $1(2) \wedge$ Move $2(1 \mathrm{C})$ & Move 3 \\
\hline
\end{tabular}




\begin{tabular}{|l|l|l|}
\hline $\mathbf{8}$ & Move $1(2 \wedge 3) \wedge$ Move $2(1 \mathrm{C})$ & Move 3 \\
\hline $\mathbf{9}$ & Move $1(1 \wedge 2)$ & Moves 2 and 3 \\
\hline
\end{tabular}

Tables 3 and 4 illustrate the obligatory moves used in the selected doctoral introductions and those that were omitted. Findings show that students in the Language option display obvious deficiencies in their knowledge of the generic structure of the research article introductions. However, the Literature option results are more encouraging with more than half of them observing the three-move structure of the CARS model.

\subsection{Table 4: Summary of Observed Generic/Schematic Structure in Literature Option}

\begin{tabular}{|l|l|l|}
\cline { 2 - 3 } \multicolumn{1}{l|}{} & \multicolumn{2}{l|}{$\begin{array}{l}\text { Observed Generic/Schematic/Cognitive-Move Structures in } \\
\text { the Texts }\end{array}$} \\
\hline Texts & Moves and $($ Stages $)$ & Move $(s)$ omitted \\
\hline 1 & Move $1(2 \wedge 3)$ & Moves 2 and 3 \\
\hline 2 & Move $1(2 \wedge 3) \wedge$ Move $2(1 \mathrm{~A})$ & Move 3 \\
\hline 3 & $\begin{array}{l}\text { Move } 1(2 \wedge 3) \wedge \text { Move } 2(1 \mathrm{~A} \wedge 1 \mathrm{~B} \wedge 1 \mathrm{D}) \wedge \\
\text { Move } 3(1 \mathrm{~A} \wedge 1 \mathrm{~B})\end{array}$ & Nil \\
\hline 4 & Move $1(2 \wedge 3)$ & Moves 2 and 3 \\
\hline 5 & $\begin{array}{l}\text { Move } 1(1 \wedge 2 \wedge 3) \wedge \text { Move } 2(1 \mathrm{~B} \wedge 1 \mathrm{D}) \wedge \\
\text { Move } 3(1 \mathrm{~A})\end{array}$ & Nil \\
\hline 6 & $\begin{array}{l}\text { Move } 1(2 \wedge 3) \wedge \text { Move 2 }(1 \mathrm{~B} \wedge 1 \mathrm{D}) \wedge \text { Move 3 } \\
(1 \mathrm{~A})\end{array}$ & Nil \\
\hline 7 & $\begin{array}{l}\text { Move } 1(1 \wedge 2 \wedge 3) \wedge \text { Move 2 }(1 \mathrm{D}) \wedge \text { Move 3 } \\
(1 \mathrm{~A})\end{array}$ & Nil \\
\hline 8 & Move $1(2 \wedge 3) \wedge$ Move 2 $(1 \mathrm{D}) \wedge$ Move 3 $(1 \mathrm{~A})$ & Nil \\
\hline 9 & Move $1(1 \wedge 2)$ & Moves 2 and 3 \\
\hline
\end{tabular}


Although it could be seen that Tables 1 and 2 show more $X$ than $\sqrt{ }$ in most obligatory stages of their research article introductions, five seminars from the Literature option conformed to the three-move schematic structure of introductions and none from the Language option as shown in Tables 3 and 4. Most seminars moved straight into review of scholarship without addressing the requirements of introductions. This explains why all the seminars have Move 1(3) "Overview of previous research". It is obvious that this category of students needs a remedial course that will address this deficiency.

In Table 5, we present a sample (not an excellent model, of course) to illustrate the CARS model of research article introduction. It incidentally is an introduction to this paper, and the writer just picked it for want of a better alternative. However, all the obligatory features of the model as well as some of the optional move structures are captured. This is meant to provide the reader with a sample of what a doctoral seminar introduction should be. 


\subsection{Table 5: Sample of Research Article Introduction Illustrating the Schematic Structure}

(1) Academic writing in tertiary institutions requires knowledge of the specialized communicative event, communicative goals and purposes of that particular discourse community. As a member of the academia, several years of experience acquired from reading students' research works ranging from undergraduate projects to masters theses and doctoral dissertations show some limitations in achieving the communicative intentions of the writers, partly, owing to poor knowledge of the conventional ways of discourse organisation in that genre. (2) Writing research article introductions and abstracts - both different genres of academic writing - has been identified as posing serious difficulties for some students who are grappling with the various final projects in partial fulfilment of their faculty requirements for graduation.. Some of the problems relate to poor knowledge of the code for academic writing which require proficiency in nominalized rather than clausal forms (Ezeifeka, 2015), knowledge of the conventions of each genre and sensitivity to cognitive structures and organizational formats (Bhatia, 1997). (3) Genre-based approach to the study of texts like research article introductions has preoccupied many researches in academic writing with the quest to determining their inherent functional patterns vis-à-vis their communicative purposes. Previous study in this area (Bakhtin, 1986, Martin, 1984, 1985; Hasan, 1978; Bhatia, 1993, 1997; Eggins, 2004) including a collection of chapters edited by Bazerman, Bonini and Figueiredo (2009), show that knowledge of generic structure of texts goes a long way in organizing text production and consumption in terms of predictable expectations and understanding of the myriad of genres in our culture.

(21A) In spite of arguments on whether genres should be understood in fixed, rigid schema, made up of stages, or whether genres are more flexible, unpredictable and heterogeneous, the need to have a uniform format for some specialized forms of writing such as academic writing which research article introduction is a part is incontrovertible. (21B)In this paper, an attempt is made to scrutinize research introductions as a genre in selected doctoral seminars of the Department of English Language and Literature, Nnamdi Azikiwe University, Awka. (21C)The paper will address the following questions: How are the introductions in the selected seminar papers organized structurally? How do these structural organizations conform with or detract from the known generic/schematic structure characterizing such a genre? How do the findings speak to the present proficiency of these students? What recommendations should be made for improving the anomaly?

(31A) The goal of this paper is therefore to discover the extent to which these selected texts from the Department of English Language and Literature conform to, or depart from, the stipulated schematic or generic structure of such a genre. Knowledge of such models and competent application of appropriate schematic structure to the writing of research introduction is germane for any budding academic who requires proficiency in language use in such a genre to be able to scale through their studies with good grades in seminar presentations as well as in their final projects. (2) This work is therefore a contribution to the English for Specific Purposes with particular emphasis on English for Academic Purposes where a needs analysis of student's present proficiency, exemplified in the sample seminars, would lead to the determination of their present proficiency, their lacks and efforts to bring about learning that will lead to target proficiency. (3) We shall proceed in this paper with reviewing the key concepts, thereafter its theoretical and methodological underpinnings. Analysis of data follows after which the paper concludes with a recommendation on the need for conscious learning, through ESP/EAP, of this important genre in academic writing. 


\section{Discussion}

We began this paper by arguing that observations at various doctoral students' seminars show that many students fall short in the knowledge of the schematic moves for research article introductions and that ESP, as an approach to language learning, could be applied to remedy the problem. Our results have confirmed this fear with more than half of the texts studied. The general inclinations of the students as observed is jumping head-on into review of literature without engaging such in defining the problem, what makes the problem a topic for empirical investigation, the motivations that triggered the study and the gap in knowledge to be filled.

It is obvious that their present proficiency in the writing of research article introductions is inadequate to tackle this highly literacy-demanding academic genre. Students will keep experiencing problems and having their seminars put down by examiners if this is not addressed.

\section{Conclusion and Recommendation}

Based on these findings, this paper is recommending a short course (two weeks) through ESP to provide remedial programmes for all doctoral students in the Department of English. The learners will comprise all postgraduate students (MA and $\mathrm{PhD}$ ) in the Department of English. Target and learning needs will be focused on, the learners being taught to be able to write research article introduction through the genre-based approach specified in this paper. This effort will no doubt bridge this knowledge gap for budding academics so that they can not only improve on their personal academic writings but also provide needed mentorship to upcoming academics. This will ensure academic growth and excellence. 


\section{Chinwe Ezeifeka}

Department of English Language \& Literature

Nnamdi Azikiwe University

Awka, Nigeria

cr.ezeifeka@unizik.edu.ng

\section{References}

Bakhtin, Mikhail. (1986). Speech genres and other late essays (V. W. McGee, Trans.). Austin: University of Texas Press

Bazerman, Charles, Bonini, Adair \& Figueiredo, Debora (Eds.) (2009).Genre in a Changing World. Colorado and Indiana: The WAC Clearing House and Parlor Press

Bhatia, Vijay K. (1993). Analysing Genre: Language Use in Professional Settings. Harlow-Essex: Longman Group.UK.

Bhatia, Vijay K. (1997). Applied Genre Analysis and ESP. In: T, Miller (Ed.). Functional Approaches to Written Text: Classroom Applications. 134-149. English Language Programmes. United States Information Agency.

Burns, A. \& Seidhofer, B. (2010) Speaking and pronunciation. In: N. Schmitt (Ed.). An Introduction to Applied Linguistics. London: Hodder, 197-214.

Carter, R.A. \& Malmkjaer, K. (2002). Text Linguistics. In: K. Malmkjaer (Ed.). The Linguistics Encyclopedia. 2nd ed. London and New York: Routledge.

Eggins, S. (2004). An introduction to systemic functional linguistics. (2nd ed.). New York, NY: Continuum.

Ezeifeka, Chinwe R. (2015). Grammatical metaphor: In search of proficiency in research abstract writing. Sage Open, JanuaryMarch 1-14.

Halliday, M. A. K. (1973). Explorations in the functions of language. London, England: Edward Arnold. 
Ezeifeka: Genre-Based Approach to the Analysis of Introductions in Doctoral Seminars of the Department of English, UNIZIK, Awka

Halliday, M.A.K. \& Matthiessen, C.M.I.M. (2004). Introduction to Functional Grammar. $3^{\text {rd }}$ ed.

Hasan, R. (1978). “Text in the Systemic-Functional Model”. In: W.U. Dressler (ed.) Current Trends in Textlinguistics (228-246) Berlin and New York: Walter de Gruyter.

Hutchinson, T. \& Waters, A. (1987).English for Specific Purposes: A Learning-Centred Approach. Cambridge University Press.

Jones, Paul \& Holmes D. (2011). Key Concepts in Communication Studies. London: Sage.

Krashen, Stephen D. (1985) The Input Hypothesis. England: Longman.

Martin, J. R. (1984). Language, Register and Genre. In F. Christie (Ed.), Children Writing: A Reader (pp. 21-29). Geelong: Deakin University Press.

Martin J.R. (1985). Process and Text: Two Aspects of Semiosis. In J. D. Benson \& W. S. Greaves (Eds.), Systemic Perspectives on Discourse, Vol. 1: Selected Theoretical Papers from the $9^{\text {th }}$ International Systemic Workshop (pp. 248-274). Amsterdam: John Benjamins.

Pare, Anthony; Starke-Meyeering, Doreen \& McAlpine, Lynn. (2009). "The Dissertation as Multi-Genre: Many Readers, Many Readings". In: C. Bazerman,, A. Bonini \& D. Figueiredo (Eds.). Genre in a Changing World. (179-194) Colorado and Indiana: The WAC Clearing House and Parlor Press.

Spat, Brenda. (2011). Writing from sources. ( $8^{\text {th }}$ edn.). Boston: Bedford/St Martin's.

Swales, John M. (2004). Research Genres: Explorations and Applications. Cambridge: Cambridge University Press.

University of Southern California. Research Guides. USC libraries. https://libguides.usc.edu/writingguide/introduction Accessed July 5, 2019 
van Dijk, T.A. (2001). Multidisciplinary CDA: A plea for diversity. In R. Wodak and M. Meyer (eds.), Methods of Critical Discourse Analysis. London: Sage, pp.95-120

Wales, K. (1989, 1997). A Dictionary of Stylistics. London: Longman. 